\title{
Technology Development of Charcoal Brequetting from Mangochi, Malawi, Central Africa
}

\author{
Vaitheeswaran Thiruvengadam* \\ Lecturer, Department of Aquaculture, DMI St. John the Baptist University, Mangochi Campus, Republic of Malawi, Central Africa \\ *Corresponding Author: Vaitheeswaran Thiruvengadam, Lecturer, Department of Aquaculture, DMI St. John the Baptist University, \\ Mangochi Campus, Republic of Malawi, Central Africa.
}

Received: November 08, 2019; Published: November 12, 2019

DOI: $10.31080 /$ ASNH.2019.03.0547

\section{Introduction}

Charcoal constitutes the primary source of urban fuel in most of African continents, basic requirement and employment opportunities of major and vital source of income and environmental degradation in rural areas. The creation, transportation and ignition of charcoal founds a life-threatening energy and economic rotation in the economics of many under developing/developed nations. Charcoal production a method called as pyrolysis (pyro "fire" and lysis "separating") of biomass. Pyrolysis is distinct as the irreversible chemical change carried about by heating the biomass in the nonappearance of oxygen. Biomass undertakes a sequence of changes and normally produces a black carbonaceous solid, called as charcoal, along with a mixture of gases and vapors. The high requirement of charcoal/firewood is rising due to the petroleum-based fuels, and effect of rapid human population growth, especially in urban areas in Mozambique, Malawi, Tanzania and Zambia.

Malawi ranks 173 of 188 countries and territories in the 2014 Human Development Index, with a population of 19.0 million [3]. Poverty in Malawi is high by global standards and, despite periods of relatively fast economic growth over the past decade, has been slow to decline. Malawi's population is expected to reach 30 million by 2030, representing an annual addition of one million people per year over the next 13 years. Further intensifying stresses on the carrying capacity of agricultural land, where currently two people share one hectare. By 2040, population density per hectare will increase to five. The prevalence of poverty is higher in rural areas than urban ones (55.9 per cent and 25.4 per cent, respectively), although rapid and unplanned urban settlements have resulted in faster growth of urban poverty (National Charcoal Strategy 20172027). Malawi currently has $341 \mathrm{MW}$ installed out of a potential
600 MW in the SRB. Seventy MW load shedding. In Malawi, the wealthiest households are concentrated in urban areas. Almost half of the rural population (46\%) falls in the two lowest wealth quintiles. Malawian people have been using for the firewood and charcoal more than $97 \%$ utilization for cooking other purposes. According to National Resilience Strategy (2018-2030) [2] have reviewed that the population of Malawi 319,000 ultra-poor, labour constrained, and vulnerable households and $15 \%$ of poor households for across all 28 districts; Up to $50 \%$ of household population with lowest welfare status. Malawi urban living households people have used for charcoal for $57 \%$. Only $7 \%$ of the population of Malawi have been using for electricity and remaining Malawian people (93\%) for provides cooking energy for urban/peri-urban region only.

\section{Impact and causes}

According to [1] have reviewed that the charcoal production unit can emit amounts of particulate matter (PM), carbon monoxide (CO), nitrate oxides ( $\mathrm{NOx}$ ) and sulphate dioxide $\left(\mathrm{SO}_{2}\right)$, hydrogen fluoride (HF), hydrogen chlorine ( $\mathrm{HCl}$ ), formaldehyde, phenol, acetic acid, xylene and toluene. In connection with to continuing deforestation of Malawian ecosystem, to meet the charcoal and firewood demand is more in 2030. Charcoal and firewood have continuous to diminish the production level, the price of charcoal and firewood too high in 2030. According to National Energy Policy (2016) have reviewed that the household air pollution by using of charcoal and firewood will increase respiratory disease viz., pneumonia.

The NCS is organized around seven inter-related pillars: promote Alternative Household Cooking Fuels; promote Adoption of Fuel-Efficient Cook-stove Technologies; promote Sustainable Wood Production; Strengthen Law Enforcement; Regulate Sustainable 
Charcoal Production; enhance Livelihoods; and, promote Information, Awareness and behavior change communications. The needs of men, women, children and vulnerable groups, and partnerships with the private sector, cut across all NCS pillars (National Resilience Strategy, 2018-2030) [2]. The new technology is being establish and time for action are needed. Together with have make a difference. Charcoal briquettes are made of all kinds of forest dry leaves, sticks, other form of litters. The biomass resources are viable, it has been alternate source of charcoal briquette Plant at Mangochi, Republic of Malawi, Central Africa [4].

Raw materials and charcoal briquettes

The most important materials like a litter in the form of (coconut shell, sawdust, woodchips, bamboo shavings, tree bark, chestnut shell, cotton, sesame, corn, sunflower, soybean stalks, rice husk, sugarcane bagasse, corncob) etc. The optimum size of material $6 \mathrm{~mm}$ and less than $10 \%$ of moisture.

How to make charcoal briquettes

Humiliating the raw materials have less than $5 \mathrm{~mm}$; Dehydrated the crushed materials to $8-12 \%$; Pressing the raw materials into briquette and carbonization, and make it charcoal powder and finally charcoal briquette.

Charcoal briquetting working principle

Briquetting is a process the biomass is compressed under high pressure and high temperature and mixed with glue (one of the binders) the raw material and end products.

\section{Bibliography}

1. Domac J and Trossero M. "Options for improved charcoal production in Belisce". North West Croatia Regional Energy Agency (2008).

2. National Charcoal Strategy. Republic of Malawi: The Ministry of Natural Resources, Energy and Mining (2017-2027): 44.

3. United Nations Development Programme (UNDP). About Malawi (2015).

4. Zulu LC. "The forbidden fuel: Charcoal, urban woodfuel demand and supply dynamics, community forest management and wood fuel policy in Malawi". Energy Policy (2010).

\section{Volume 3 Issue 12 December 2019}

(C) All rights are reserved by Vaitheeswaran

\section{Thiruvengadam.}

Citation: Vaitheeswaran Thiruvengadam. "Technology Development of Charcoal Brequetting from Mangochi, Malawi, Central Africa". Acta Scientific Nutritional Health 3.12 (2019): 137-138. 